\title{
Introduction: \\ The Dynamics of Language and Inequality
}

\author{
Joel Windle, Dánie de Jesus and Lesley Bartlett
}

The concept of boundaries has long been central to the field of language studies, through classifications of linguistic forms and speakers. More recently, linguistic and discursive boundaries, along with boundary crossing and gatekeeping, have gained attention within work attending to the generation of inequalities, particularly through educational institutions (see, for example, Block, 2012; Heller \& McElhinny, 2017). The present volume contributes new scholarship from the global south to this line of investigation. One motivation for (re)focusing attention on boundaries is a trend towards viewing geographical and linguistic divisions as of limited and fading importance, swept away by the currents of globalization and replaced by metaphors of flow and movement. Global flows, however, remain structured and articulated by boundaries, which do not merely stand in their way but help to constitute them (Gerrard \& Sriprakesh, 2018; Stroud \& Prinsloo, 2015). It is important, therefore, to show how, and where, linguistic inequalities continue to work through both old and new types of boundaries, contributing to the geopolitics of colonialism, capitalism and myriad, interwoven, forms of social life that structure both oppression and resistance.

Boundaries can be thought of as relational constructs that mark exclusion, as well as the terms upon which admission to groups, institutions, territories, identities or practices may be granted (Oommen, 1995). Boundaries are useful metaphors for analysing power because they draw attention to how difference is produced and enforced in externalised and durable ways, particularly through the establishment of a center-periphery relationship. Although boundaries may vary in rigidity and stability, it is at the moments of boundary crossing, or attempted crossings, that they are brought to life as central elements of social relations (Anzaldúa, 1987). Boundaries can be enacted through linguistic ideologies, language policies, curriculum choices, exclusionary identity 
constructions and communicative practices - topics examined in the chapters that follow.

Importantly, boundaries have the capacity of binding together both the included and the excluded, constituting an essential dimension of relations of expropriation, exploitation and domination. Boundaries and boundary-making may, indeed, hold strongest sway over those who are held outside of their limits, yet who remain part of the same social world as the priviledged centre, interpellated even as they are held apart (Feltran, 2011). As Feltran observes,

Where there is a boundary, there is communication of an unequal and controlled kind. If there is a boundary, it is precisely to control communication between the sides ... Where there is a boundary, there is conflict. Even if it is latent. If a boundary can be contested, it is common, particularly in extremely hierarchical and unequal societies, that latency gives way to violence. (2011: 15, our translation)

Those who are engaged in hybrid or boundary-crossing practices are often in the firing line of literal and symbolic border policing, considered subversive, dangerous and shameful. It is no accident that Borderlands, a book that described the US-Mexican border as 'una herida abierta where the Third World grates against the first and bleeds' (Aznaldúa, 1987: 25), was banned in Arizona schools in 2012 as part of a xenophobic backlash against Latino studies.

The present volume focuses on the divisions produced by linguistic inequalities in settings in the Global South that are strongly shaped by imperialism, including chapters from the Pacific, Asia, Middle East, Africa and Latin America. As a publication articulated by scholars who are connected primarily through Brazil, a number of chapters address this setting, even as they draw attention to the shifting territorial and linguistic boundaries of this country. For example, Chapter 1 not only points out the relatively recent inclusion of Amazonian regions into Brazil, but the arbitrary violence of the establishment of colonial boundaries, evident in the fate of the speakers of Amazonian lingua geral, an indigenous-based lingua franca, almost half of whom were killed in the Paraguayan War (18641870). Impoverished conscripts from the Amazon region were sent to their deaths in Paraguay by Portuguese-speaking officers they little understood:

many soldiers from the 5th Infantry Battalion, who could not even understand the orders of their commander [in Portuguese], died on the battlefields of Paraguay as 'volunteers of the homeland', speaking a language understood by the enemy but unknown in their own trenches. (Freire, 2011: 102)

The annihilation of speakers of Indigenous languages and imposition of European languages also takes more subtle forms, through the 
authorising of exclusive linguistic frameworks for schooling, scholarship, business and government. The hegemony of English is evident in publishing practices in the global south (see Chapter 7), and in more positive portrayals of English as a lingua franca capable of reducing boundaries. For example, the opening lines of Brazil's national curriculum for English read:

To learn the English language allows for the creation of new forms of student engagement and participation in an increasingly globalized and plural social world, in which the borders between countries and personal, local, regional, national, and transnational interests are continually more diffuse and contradictory. ${ }^{1}$ (Ministério da Educação, 2018: 239, our emphasis)

In such a declaration, the relationship between language and social inequality is implicitly about the social valuing of some speakers, and thus of some languages or features of languages. It is essential to recognize how this may vary by context and how bureaucratic institutions, such as schooling, may reinforce certain inequalities (for an overview, see Philips, 2006).

Inequality is also expressed and reinforced through quotidian linguistic practices. Bourdieu $(1984,1990)$ illuminates how some ways of expressing oneself are more socially valued than others, depending upon the context. As scholars in linguistic anthropology have shown, 'ideas can be inculcated through speech that is persuasive in part because of its prestigious nature' (Philips, 2006: 476). 'Authoritative speech' describes the concept that 'by speaking in a particular style which is highly valued and/or associated with authority, or by speaking from within a particular discourse genre that is authoritative or associated with authoritative people, a speaker is more persuasive, more convincing, and more attended to' (2006: 476). Authoritative speech can be mapped onto racialized social hierarchies, as Chapter 2 shows.

The boundaries defining linguistic and social inequality are thus inherently shaped by what has come to be termed language ideologies. Language ideology, as succinctly defined by Alan Rumsey (1990), entails 'shared bodies of commonsense notions about the nature of language in the world' (1990: 346). Language ideologies 'represent the perception of language and discourse that is constructed in the interest of a specific social or cultural group' (Kroskrity, 2006: 501). They work in powerful ways on a micro-political level through affect and the generation of emotions such as shame, as Chapters 4 and 5 show in relation to Senegal and Kiribati.

The boundaries identified in the chapters that follow are constituted by divergences in meaning which necessarily involve heterogeneity. As such, each chapter questions the ways in which heteronormativist, 
monolingualist or racist discourses are legitimized. Boundaries, as we understand them, are constructed through dichotomies that reinforce hegemonic positions and legitimize oppressive norms of conventional cultural ideas of gender/race/language/culture. Under conditions of conservatism, repression and censorship, teachers and researchers need to deal with the relational, negotiated, and fluid nature of knowledge alongside its boundedness within ideological categories - a task undertaken in the final section of the book. Following on from this idea, the notion that meaning becomes plural and is influenced by 'otherness' is an integral element of the perspectives we collectively support in this volume.

\section{Structure of the Book}

This volume interrogates questions of social power, affect, identity construction, and imperialism as manifest in the relationships between language and exclusion, marginalisation and isolation, and as structured institutionally and pedagogically by schooling. The opening section presents work that takes a historical approach to boundaries (Chapters 1 and 2), and which identifies important shifts in boundary maintenance with the advent of digital technologies (Chapter 3). Section 2 focuses on cases in which language ideologies play an important role in constructing and maintaining inequalities along national and transnational scales in schools, universities and communities. Section 3 strikes a more optimistic note, with examples of transgression and resistance that challenge oppressive linguistic and social boundaries.

\section{Section 1: The Shifting Boundaries of Linguistic Inequality}

All boundaries have histories that include both the rules of differenciation and exclusion that structure them, and of the populations subjected to these rules. These histories are embedded in wider social, political and economic contexts, which, when ignored, allow boundaries to gain universalizing and naturalizing qualities that often strengthen them. In Chapter 1, Dennys Silva-Reis and Marcos Bagno break apart a number of dehistoricized boundaries that structure contemporary Brazilian nationalism. The first of these is the myth of a territory equivalent to the Brazilian nation in colonial times, and the second of a unified process of colonization. In fact, colonization of the Amazon was undertaken long after that of other regions, through a separate colonial administration, and through a different language, Amazonian língua geral.

Chapter 2 provides a critical overview of theoretical models of language and educational inequality. The piece pointedly asks how well concepts developed in other times and places apply to educational and linguistic processes in Brazil, and what distortions or misunderstandings 
are generated from their misapplication. This chapter, then, questions the mobility and universality of theory about language and inequality. The chapter ends with discussion of a teacher education project in public schools, which points to how shifts in racial identification and (anti)racism in Brazil demand new theoretical tools for both properly recognising racialized social relations and challenging racism in schools, while also affirming other marginalised identities.

In Chapter 3, Daariimaa Marav shows how a long-standing urban-rural divide is maintained and even consolidated in the context of a shift in the language of power (from Russian to English), and the arrival of digital technologies. Marav examines how Mongolian university students from urban and rural backgrounds majoring in English use digital literacies in their daily lives. She shows how prior advantages are magnified through the types of work required in university classes. In turn, the students' engagement with digital technologies in and out of university and their English language proficiency affect their status, prestige and knowledge, reinforcing a historic rural-urban divide through new forms of symbolic capital.

\section{Section 2: Language, Ideology and Inequality}

In Chapter 4, Teresa Speciale builds upon Bourdieu's understanding of linguistic capital and, using affect theory and a decoloniality lens, shows how shaming perpetuates language inequalities in a Senegalese French-English bilingual school. African languages come to be defined as the antithesis of 'global' practices that afford opportunities for future success. The chapter argues that a masking of linguistic shaming policies under the guise of globalising education, in combination with students' privileged backgrounds, leads to a cycle of shaming wherein dominant language ideologies, hierarchies, and inequalities continue to be framed as not only legitimate but also inevitable.

Drawing together themes introduced throughout the volume, in Chapter 5 Indika Liyanage and Suresh Canagarajah analyse how nationals and international development workers on the small Pacific island nation of Kiribati demonstrate conflicting orientations to shame relating to using and learning English. They find a striking tension in language ideologies and affect: While international experts denigrate shame, treat it as backwards and limiting, and seek strategies to move Kiribati people to desire English, the local people treat shame as a positive mechanism to affirm community cohesion, regulate cultural change, and manage multilingual repertoires. The authors argue that the unresolved tensions produce a challenge for local ELT pedagogies.

Chapter 6 takes up questions related to English language teaching in Brazil. Junia Zaidan shows how, despite declarations that Brazilians will appropriate and indigenize the English language, the ideology of native 
speakerism nevertheless persists. The author examines the intimate linkages between native speakerism and instrumentalist, economic justifications of foreign language instruction.

In Chapter 7, the empirical and theoricital focus broadens to analyse knowledge production and circulation on education within a globalizing academic field. The authors ask how the criteria for excellence in Brazilian publishing reflect global language inequalities. To do so, they consider the national and international positioning strategies of the journal Educação em Revista (Education in Review), produced by the Postgraduate Program in Education of Federal University of Minas Gerais (UFMG). The chapter asks how the Coordination for the Improvement of Higher Education Personnel (CAPES) evaluation policy shaped the strategies that journals use to consolidate a reputation for quality.

\section{Section 3: Transgression and Agency}

In Chapter 8, Carolyn McKinney draws on decoloniality theory to analyze the anglonormativity underpinning South Africa's language in education policy. The chapter shows the persistence of monolingual language ideologies, despite the revolutionary change in langauge policy. Furthermore, based on empirical data, it argues that transgressing socially constructed language boundaries and disrupting monolingual language ideologies is essential to the repositioning of language as a resource for learning in South African schooling.

In Chapter 9, Dánie Marcelo de Jesus introduces themes of the discursively constructed body into discussions of inequality. He describes an effort to counter the silences around gendered and sexual identities in language classes and the preparation of English language educators. The chapter shows how this work provided space for and stimulated debate on gender-related issues within language teacher education at a Brazilian university, in an attempt to foster resistance against gender inequality.

Osman Z. Barnawi and Phan Le Ha extend this concern with gendered inequality and language. In Chapter 10, they first discuss how the English language has been positioned as key to the unfolding transformations of gender roles in Saudi Arabia, where national reforms position English as a language of new economy and social transformations. The authors contrast this broad-scale context with the dilemmas expressed by Saudi, female, Western-trained TESOL teachers as they contemplate their own new freedoms and the role English might play in women's empowerment.

\section{Note}

(1) 'Aprender a língua inglesa propicia a criação de novas formas de engajamento e participação dos alunos em um mundo social cada vez mais globalizado e plural, em que as fronteiras entre países e interesses pessoais, locais, regionais, nacionais e transnacionais estão cada vez mais difusas e contraditórias.' 


\section{References}

Anzaldúa, G. (1987) Borderlands: La frontera. San Francisco: Aunt Lute Books.

Block, D. (2012) Economising globalisation and identity in applied linguistics in neoliberal times. In D. Block, J. Gray and M. Holborow (eds) Neoliberalism and Applied Linguistics (pp. 56-85). New York: Routledge.

Bourdieu, P. (1984) Distinction: A Social Critique of the Judgement of Taste. Cambridge, MA: Harvard University Press.

Bourdieu, P. and Passeron, J.C. (eds) (1990) Reproduction in Education, Society, and Culture. London: Sage.

Feltran, G. (2011) Fronteiras de tensão: politica e violência nas periferias de São Paulo. São Paulo: Editora Unesp.

Gerrard, J. and Sriprakash, A. (2018) Migration and the borders of education. International Studies in Sociology of Education 27 (2-3), 107-110.

Heller, M. and McElhinny, B. (2017) Language, Capitalism, Colonialism: Toward a Critical History. Toronto: Toronto University Press.

Kroskrity, P. (2006) Language ideologies. In A. Duranti (ed.) A Companion to Linguistic Anthropology (pp. 496-517). London: Wiley-Blackwell.

Ministério da Educação Brazil (2018) Base Nacional Commum Curricular. Brasília: MEC.

Oommen, T.K. (1995) Contested boundaries and emerging pluralism. International Sociology 10 (3), 251-268.

Philips, S. (2006) Language and social inequality. In A. Duranti (ed.) A Companion to Linguistic Anthropology (pp. 474-495). London: Wiley-Blackwell.

Rumsey, A. (1990) Wording, meaning, and linguistic ideology. American Anthropologist 92, 346-361.

Stroud, C. and Prinsloo, M. (2015) Language, Literacy and Diversity: Moving Words (Vol. 7). New York: Routledge. 
